\title{
Factors related to obesity among Iranian men: results from the National Health Survey
}

\author{
Enayatollah Bakhshi ${ }^{1,2}$, Kazem Mohammad ${ }^{1, *}$, Mohammad R Eshraghian ${ }^{1}$ and \\ Behiat Seifi ${ }^{3}$ \\ 'Department of Biostatistics, School of Public Health and Institute of Public Health Research, Tehran University of \\ Medical Sciences, Tehran 141556446, Islamic Republic of Iran: ${ }^{2}$ Department of Statistics and Computer, \\ University of Welfare and Rehabilitation Sciences, Tehran, Islamic Republic of Iran: ${ }^{3}$ Department of Physiology, \\ Medicine School, Tehran University of Medical Sciences, Tehran, Islamic Republic of Iran
}

Submitted 15 May 2009: Accepted 29 December 2009: First published online 4 May 2010

\begin{abstract}
Objective: To our knowledge, only a few Iranian studies have investigated factors associated with obesity among men. The aims of the present study were to explore the associations between sociodemographic factors, smoking and obesity in Iranian men and compare these associations between Iranian men and women. Design: We used data from the National Health Survey in Iran. A generalised estimating equations model included 11697 men and 14854 women aged 20-69 years (12850 households). Body weight and height were objectively measured. BMI was calculated as $\mathrm{kg} / \mathrm{m}^{2}$, and subjects were classified into obese (BMI $\geq 30$ $\mathrm{kg} / \mathrm{m}^{2}$ ) and non-obese $\left(\mathrm{BMI}<30 \mathrm{~kg} / \mathrm{m}^{2}\right)$.

Results: Among men, adjusted obesity OR were 0.62 (95\% CI 0.52, 0.74), 1.09 (95\% CI 0.90, 1.32), 1.003 (95\% CI 1.00, 1.007) and 0.57 (95\% CI 0.40, 0.81) for smokers, married, economic index and active workforce groups, respectively. Using low education as the reference group, the obesity OR for men were 1.06 (95\% CI $0.89,1.26)$ and $0.75(95 \%$ CI $0.57,0.99)$ for the moderate and high education groups, respectively. Using rural as the reference group, the obesity OR was $1 \cdot 87(95 \%$ CI $1 \cdot 56,2 \cdot 26)$ for urban men.

Conclusions: Our findings may point towards a better understanding of the social and cultural mechanisms of obesity in Iranian men. The above sociodemographic factors are large contributors to obesity and provide the greatest opportunity for actions and interventions designed for prevention and treatment.
\end{abstract}

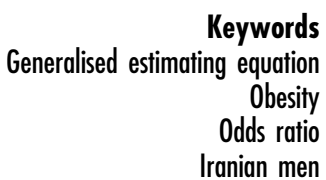

The obesity epidemic has become a worldwide phenomenon in recent years ${ }^{(1,2)}$. Nearly half a billion of the world's population is now considered to be overweight or obese $^{(3)}$. In 2003-2004, approximately $32 \%$ of the US adult population was obese ${ }^{(4)}$. Obesity in men is considered a major problem in Europe and the prevalence of obesity has increased by $10-40 \%$ in the past 10 years ${ }^{(5)}$. Almost one-third of adult Canadians are at increased risk of disability, disease and premature death due to obesity ${ }^{(6)}$. In 2001, 58\% of Australian men and $42 \%$ of Australian women were classified as overweight or obese ${ }^{(7)}$. Obesity is not only classified as a disease in its own right, but also has been reported to be a risk factor for CVD, diabetes, hypertension, some cancers and other diseases ${ }^{(8-15)}$.

Obesity is caused by many factors. Most studies have investigated the relationship between sociodemographic factors and obesity. One potential predictor could be age ${ }^{(16-19)}$. Another predictor is socio-economic status that has shown an inverse relation with obesity among women, but weaker and less consistent among men ${ }^{(20-23)}$.

In low-income countries, obesity is more common among middle-aged women, people of higher socioeconomic status and people living in urban communities ${ }^{(19,24,25)}$. Molarius et al. ${ }^{(22)}$ found that low education was associated with a higher BMI (BMI was calculated as $\mathrm{kg} / \mathrm{m}^{2}$ ) in about half of the male and in almost all of the female populations of the WHO MONICA Project.

Although the association of obesity with smoking has been analysed in many studies, the findings are not consistent $^{(26-31)}$.

A study that had a sample size sufficient to explore factors associated with obesity among Iranian men has not been carried out in Iran. The primary aim of the present study was to examine the relationship between sociodemographic factors, smoking and obesity among men by using cross-sectional data from the National 
Health Survey in Iran (NHSI). A secondary aim was to compare these associations between men and women.

\section{Experimental methods}

\section{Data set examined}

The NHSI is a survey designed to gain comprehensive knowledge and information about health-care problems and difficulties in Iran during 1999-2000. All citizens living in Iran were considered as the survey population. Preliminary studies and preparation of the questionnaire took 4 months, but finally, in August 1990, this project was started in all provinces with the help of medical universities, the Undersecretary for Primary Health and the Blood Transfusion Centre. The pilot study was carried out in Semnan province, and later other provinces were also studied. For certain information, the subject sample was the family and for other it was the person (age 2-69 years). Household was defined as those living in the same residence, participating in the household's expenses and usually eating together. Any individual living single was also considered a household. Sampling was conducted on the basis of the cluster method, and each cluster consists of eight households. The choice of eight households for the cluster size was based on the $1 \mathrm{~d}$ performance capacity of the data collection group: four professional persons (two physicians, one interviewer and one lab technician). The statistical framework was based on the household lists available in every Health Department in the provinces, usually updated annually. The ratio of the sample size to the total population was taken as 1:1000 (according to the latest census figures). Where household lists were available, selection of the cluster was made systematically. In the present study, 11697 men and 14854 women (12850 households) aged 20-69 years were examined. We excluded pregnant women from the analyses. The study is approved by the Ethics Committee of the Tehran University of Medical Sciences.

\section{Measurements}

Data derived from the medical history, physical examination and laboratory findings were recorded. Laboratory studies were carried out for $84.6 \%$ of the total population studied. Paraclinical tests were performed in the laboratories of each province. They included haemoglobin and haematocrit levels, mean cell volume, hepatitis B surface antigen and stool examination. Six different questionnaires were completed. Questionnaire 1 contained general information about cluster; questionnaire 2 contained information about the standard of hygiene in the household; questionnaire 3 contained information about foodstuffs ingested by the family within the last $48 \mathrm{~h}$; questionnaire 4 contained questions about hygienic conditions, medical history, general physical state and psychological health; questionnaire 5 contained information about clinical findings detected by the examining physicians; and questionnaire 6 contained information about the results of blood and stool examinations.

Height was measured without shoes to the nearest $5 \mathrm{~mm}$. Weight was measured to the nearest $0 \cdot 1 \mathrm{~kg}$ with the subject in light indoor clothes, with emptied pockets and without shoes. Weight and height were, respectively, measured using calibrated precision scales and portable wall-mounted stadiometers, following standardised procedures. BMI, used as a measure for relative weight, was calculated as $\mathrm{kg} / \mathrm{m}^{2}$, and subjects were classified into obese $\left(B M I \geq 30 \mathrm{~kg} / \mathrm{m}^{2}\right)$ and non-obese $\left(\mathrm{BMI}<30 \mathrm{~kg} / \mathrm{m}^{2}\right)$.

\section{Independent variables}

Information about the respondents' age was based on their self-reported birth year, and subjects were stratified into five 10-year age groups (20-29, 30-39, 40-49, 50-59 and 60-69 years).

Education was defined as the total number of years of education. The respondents were categorised into three groups: those with low (0-8 years), moderate (9-12 years) or high (more than 12 years) education. The three categories used two dummy variables.

Economic index was defined as square metre of living place divided by number of people in household.

The original questionnaire item included twelve response categories. For this analysis, housewife, student, retired and unemployed were grouped into one category named 'nonactive workforce' $v$. 'active workforce' (others). The subjects were grouped according to their place of residence as living in cities (urban) or villages (rural). Smoking status was dichotomised into smoker $v$. non-smoker. To make the marital status variable, it was dichotomised into legally married and non-married groups.

\section{Statistical analysis}

The generalised estimating equation (GEE) approach was used to carry out logistic regression for correlated dichotomous responses. As subjects' responses are correlated within the same household, the GEE model with a logit link and exchangeable correlation structure were used to model the relationship between the odds of obesity and age, education, economic index, workforce, smoking, marital status and place of residence. An interaction was found between sex and educational level, and hence the results were presented separately for men and women. All twoway interaction terms were dropped from the models, because they were not statistically significant. The results are presented as OR and their 95\% CI. All analyses were carried out using the SAS statistical software package version $9 \cdot 1$ (SAS Institute, Cary, NC, USA).

\section{Results}

The mean BMI of men was $23.91 \mathrm{~kg} / \mathrm{m}^{2}$ (95\% CI $23 \cdot 84$, $23 \cdot 98)$. The women had a mean BMI of $25 \cdot 3 \mathrm{~kg} / \mathrm{m}^{2}(95 \%$ 
Table 1 Mean BMI by sex and age group in a random sample of 26551 men and women in Iran, 1999-2000

\begin{tabular}{|c|c|c|c|c|c|c|c|}
\hline \multirow[b]{3}{*}{ Age group (years) } & \multirow[b]{3}{*}{$n$} & \multicolumn{2}{|l|}{ Men } & \multicolumn{3}{|c|}{ Women } & \multirow[b]{3}{*}{$P$ value } \\
\hline & & \multicolumn{2}{|c|}{ BMI $\left(\mathrm{kg} / \mathrm{m}^{2}\right)$} & \multirow[b]{2}{*}{$n$} & \multicolumn{2}{|c|}{ BMI $\left(\mathrm{kg} / \mathrm{m}^{2}\right)$} & \\
\hline & & Mean & SD & & Mean & SD & \\
\hline 20-29 & 3689 & $22 \cdot 64$ & $3 \cdot 43$ & 5346 & $23 \cdot 50$ & $4 \cdot 50$ & $<0.001$ \\
\hline 30-39 & 3283 & $24 \cdot 27$ & $3 \cdot 73$ & 3999 & $25 \cdot 94$ & 4.92 & $<0.001$ \\
\hline $40-49$ & 2266 & 24.96 & 3.96 & 2696 & $26 \cdot 78$ & 5.07 & $<0.001$ \\
\hline 50-59 & 1241 & $24 \cdot 63$ & $3 \cdot 88$ & 1497 & $26 \cdot 91$ & 4.91 & $<0.001$ \\
\hline $60-69$ & 1218 & 24.09 & 3.96 & 1316 & $25 \cdot 83$ & 4.91 & $<0.001$ \\
\hline All & 11697 & 23.91 & $3 \cdot 83$ & 14854 & $25 \cdot 30$ & 4.96 & $<0.001$ \\
\hline
\end{tabular}

Table 2 Prevalence of obesity* according to sex, sociodemographic characteristics and smoking in a random sample of 26551 men and women in Iran, 1999-2000

\begin{tabular}{|c|c|c|c|c|c|}
\hline \multirow[b]{2}{*}{ Variable } & \multicolumn{2}{|c|}{ Men } & \multicolumn{2}{|c|}{ Women } & \multirow[b]{2}{*}{$P$ value } \\
\hline & $n$ & $\%$ & $n$ & $\%$ & \\
\hline \multicolumn{6}{|c|}{ Age group (years) } \\
\hline $20-29$ & 118 & $3 \cdot 2$ & 479 & $9 \cdot 0$ & $<0.001$ \\
\hline $30-39$ & 222 & $6 \cdot 8$ & 788 & $19 \cdot 1$ & $<0.001$ \\
\hline $40-49$ & 228 & $10 \cdot 1$ & 683 & $25 \cdot 3$ & $<0.001$ \\
\hline $50-59$ & 114 & $9 \cdot 2$ & 382 & $25 \cdot 5$ & $<0.001$ \\
\hline $60-69$ & 104 & $8 \cdot \overline{5}$ & 237 & $18 \cdot 0$ & $<0.001$ \\
\hline \multicolumn{6}{|l|}{ Education level } \\
\hline Low & 480 & $6 \cdot 8$ & 2056 & $18 \cdot 7$ & $<0.001$ \\
\hline Moderate & 234 & $6 \cdot 9$ & 449 & $14 \cdot 8$ & $<0.001$ \\
\hline High & \multirow{2}{*}{\multicolumn{2}{|c|}{$0.26^{5.1}$}} & 64 & $7 \cdot 9$ & 0.028 \\
\hline$P$ value & & & \multicolumn{2}{|c|}{$<0.001$} & \\
\hline \multicolumn{6}{|c|}{ Place of residence } \\
\hline Urban & 619 & $8 \cdot 0$ & 1968 & $20 \cdot 5$ & $<0.001$ \\
\hline Rural & 167 & $4 \cdot 2$ & 601 & $11 \cdot 5$ & $<0.001$ \\
\hline$P$ value & \multicolumn{2}{|c|}{$<0.001$} & \multicolumn{2}{|c|}{$<0.001$} & \\
\hline \multicolumn{6}{|l|}{ Workforce } \\
\hline Inactive & 750 & $7 \cdot 1$ & 2407 & $17 \cdot 8$ & $<0.001$ \\
\hline Active & 36 & $3 \cdot 0$ & 162 & 11.9 & $<0.001$ \\
\hline$P$ value & \multicolumn{2}{|c|}{$<0.001$} & \multicolumn{2}{|c|}{$<0.001$} & \\
\hline \multicolumn{6}{|l|}{ Smoking status } \\
\hline Non-smoker & 605 & $7 \cdot 4$ & 2526 & $17 \cdot 3$ & $<0.001$ \\
\hline Smoker & 181 & $5 \cdot 2$ & 43 & $15 \cdot 4$ & $<0.001$ \\
\hline$P$ value & \multicolumn{2}{|c|}{$<0.001$} & \multicolumn{2}{|c|}{0.38} & \\
\hline \multicolumn{6}{|l|}{ Marital status } \\
\hline Non-married & 146 & $6 \cdot 2$ & 437 & $15 \cdot 7$ & $<0.001$ \\
\hline Married & 640 & $6 \cdot \overline{9}$ & 2132 & $17 \cdot 7$ & $<0.001$ \\
\hline$P$ value & \multicolumn{2}{|c|}{0.26} & \multicolumn{2}{|c|}{0.02} & \\
\hline
\end{tabular}

*Obesity, $\mathrm{BMI} \geq 30 \mathrm{~kg} / \mathrm{m}^{2}$.

CI $24 \cdot 5,26 \cdot 1)$. Table 1 shows that the mean BMI of women was higher than that of men in all age groups. As the $P$ values indicate, these differences were clearly statistically significant.

Table 2 illustrates that obesity was less prevalent among the highly educated women. The prevalence of obesity was higher among men who were non-smokers, inactive in the workforce and who resided in cities. The prevalence of obesity was higher among women who were married, inactive in the workforce and who resided in cities.

We used a GEE model, which includes age, education level, economic index, workforce level, smoking status,
Table 3 Adjusted* obesity† OR, among 26551 Iranian adults in the GEE analysis, 1999-2000

\begin{tabular}{|c|c|c|c|c|}
\hline \multirow[b]{2}{*}{ Variable } & \multicolumn{2}{|r|}{ Men } & \multicolumn{2}{|c|}{ Women } \\
\hline & OR & $95 \% \mathrm{Cl}$ & OR & $95 \% \mathrm{Cl}$ \\
\hline \multicolumn{5}{|c|}{ Age group (years) } \\
\hline $20-29$ & 1.00 & & 1.00 & \\
\hline 30-39 & $2 \cdot 05$ & $1 \cdot 63,2 \cdot 59$ & $2 \cdot 30$ & $2 \cdot 03,2 \cdot 60$ \\
\hline $40-49$ & $3 \cdot 17$ & $2 \cdot 51,4 \cdot 01$ & 3.09 & $2 \cdot 71,3 \cdot 52$ \\
\hline $50-59$ & $2 \cdot 80$ & $2 \cdot 14,3 \cdot 67$ & $3 \cdot 01$ & $2.57,3.53$ \\
\hline $60-69$ & $2 \cdot 73$ & $2 \cdot 06,3 \cdot 62$ & $1 \cdot 79$ & $1 \cdot 49,2 \cdot 16$ \\
\hline \multicolumn{5}{|l|}{ Education level } \\
\hline Low & $1 \cdot 00$ & & $1 \cdot 00$ & \\
\hline Moderate & 1.06 & $0 \cdot 89,1 \cdot 26$ & 0.77 & $0 \cdot 68,0.88$ \\
\hline High & 0.75 & $0.57,0.99$ & 0.43 & $0.33,0.57$ \\
\hline \multicolumn{5}{|l|}{ Workforce } \\
\hline Inactive & 1.00 & & 1.00 & \\
\hline Active & 0.57 & $0 \cdot 40,0 \cdot 81$ & 0.79 & $0.69,0.96$ \\
\hline \multicolumn{5}{|l|}{ Smoking status } \\
\hline Non-smoker & $1 \cdot 00$ & & $1 \cdot 00$ & \\
\hline Smoker & 0.62 & $0.52,0.74$ & $0 \cdot 70$ & $0.50,0.97$ \\
\hline \multicolumn{5}{|l|}{ Marital status } \\
\hline Non-married & $1 \cdot 00$ & & $1 \cdot 00$ & \\
\hline Married & 1.09 & $0 \cdot 90,1 \cdot 32$ & $1 \cdot 16$ & $1 \cdot 03,1 \cdot 31$ \\
\hline \multicolumn{5}{|c|}{ Place of residence } \\
\hline Rural & $1 \cdot 00$ & & $1 \cdot 00$ & \\
\hline Urban & $1 \cdot 87$ & $1 \cdot 56,2 \cdot 26$ & $2 \cdot 06$ & $1 \cdot 85,2 \cdot 29$ \\
\hline Economy index & $1 \cdot 003$ & $1 \cdot 00,1 \cdot 007$ & $1 \cdot 004$ & $1.002,1.006$ \\
\hline
\end{tabular}

GEE, generalised estimating equations.

${ }^{*}$ Adjusted for all other variables.

tObesity, BMI $\geq 30 \mathrm{~kg} / \mathrm{m}^{2}$.

marital status, place of residence and sex. After adjustment for other variables, the adjusted OR and 95\% CI were calculated (Table 3). All results are presented separately for men and women.

Among men, using 20-29 years as the reference group, the adjusted obesity OR for age groups 30-39, 40-49, 50-59 and 60-69 years were $2 \cdot 05$ (95\% CI $1 \cdot 63,2 \cdot 59)$, $3 \cdot 17$ (95\% CI $2 \cdot 51,4 \cdot 01), 2 \cdot 80$ (95\% CI $2 \cdot 14,3 \cdot 67)$ and $2 \cdot 73$ (95\% CI 2.06, 3.62), respectively. Among women, the adjusted obesity OR for age groups 30-39, 40-49, 50-59 and 60-69 years were $2 \cdot 30$ (95\% CI 2.03, 2.60), $3 \cdot 09$ (95\% CI $2 \cdot 71,3 \cdot 52), 3 \cdot 01$ (95\% CI $2 \cdot 57,3 \cdot 53)$ and $1 \cdot 80(95 \%$ CI $1 \cdot 49,2 \cdot 16)$, respectively.

An association was observed between economic index and obesity. Adjusted obesity OR were 1.003 (95\% CI $1 \cdot 00,1 \cdot 007)$ and $1 \cdot 004(95 \%$ CI 1.002, 1.006) for men and 
women, respectively. In addition, for $1 \mathrm{~m}^{2}$ increase in economic index, the OR of obesity was increased by $0 \cdot 3 \%$ among men and $0 \cdot 4 \%$ among women.

Married women were more obese. The adjusted obesity OR was $1 \cdot 16$ (95\% CI $1 \cdot 03,1 \cdot 31)$. Among men, this association was not significant $\left(\mathrm{OR}_{\mathrm{a}}=1 \cdot 09(95 \% \mathrm{CI} 0 \cdot 90,1 \cdot 32)\right)$.

We observed an association between place of residence and obesity. The adjusted obesity OR were 1.88 (95\% CI $1 \cdot 56,2 \cdot 26)$ and $2 \cdot 06$ (95\% CI $1 \cdot 85,2 \cdot 29)$ for urban men and women, respectively.

We found a statistically significant inverse association between educational level and obesity among women. Using low level as the reference group, the adjusted OR for moderate level for men and women were 1.06 (95\% CI $0 \cdot 89,1 \cdot 26)$ and $0 \cdot 77(95 \%$ CI $0 \cdot 68,0 \cdot 88)$, respectively. The adjusted OR for high level for men and women were $\left(\mathrm{OR}_{\mathrm{a}}=0.75(95 \% \mathrm{CI} 0.57,0.99)\right)$ and $\left(\mathrm{OR}_{\mathrm{a}}=0.43(95 \%\right.$ CI $0 \cdot 33,0 \cdot 57)$ ), respectively.

An inverse association was observed between workforce level and obesity among both sexes. For active participants, the adjusted OR were 0.57 (95\% CI 0.40, $0 \cdot 81)$ and $0.79(95 \%$ CI $0 \cdot 66,0 \cdot 96)$ for men and women, respectively.

In general, smokers were less obese than non-smokers. The adjusted OR was $0.62(95 \%$ CI $0.52,0.74)$ and 0.70 (95\% CI $0.50,0.97)$ for men and women, respectively.

\section{Discussion}

Concern about the increased prevalence of obesity has heightened interest in the association between sociodemographic factors and smoking with obesity among Iranian households. In the present cross-sectional study, we found obesity OR by identifying a variety of sociodemographic factors and smoking that are associated with obesity. In all age groups, women had greater prevalence of obesity than men, especially in the 30-40-year age group. An association was observed between age and obesity. Similar patterns were observed in other studies from Iran ${ }^{(32-37)}$ and other countries ${ }^{(4,16)}$.

Our findings indicate that obesity is inversely associated with high education level in both sexes, but with moderate education level only in women.

In some studies, there was a significant negative association between education and obesity in both sexes $^{(33,38)}$, but some other studies showed a negative association of education with obesity in women, whereas in men there was no association or even a positive association between education and obesity ${ }^{(39-44)}$. The negative association between education and obesity has also been shown in other studies from Iran ${ }^{(35,38,45)}$. Our findings on consistent educational variation of obesity in men and women are similar to those of other studies ${ }^{(17,20)}$. Iranian adults with high education may be more concerned about obesity and have higher awareness regarding the consequences of obesity. The difference of obesity among highly educated men and women may have a significant public health impact and further work is needed to understand this difference.

In our study, in contrast with some earlier studies ${ }^{(31)}$, the prevalence of obesity was found to be lower among smokers than among non-smokers in both sexes. The inverse association seen between smoking and obesity should not be used to counteract the efforts undertaken against this habit. Biological mechanisms as well as psychological factors may be involved. An increase of energy expenditure while smoking, both in resting and in light physical activity conditions, may relate to lower prevalence of obesity in smokers. Our results are consistent with the findings of most other studies ${ }^{(26-30)}$.

Men and women who are inactive in the workforce had a higher prevalence of obesity than men and women who are active in the workforce. Obesity may be more acceptable among unemployed persons. It is also possible that there is more discrimination against the obese, or obese people may end up in lower status jobs through stronger selective processes in Iran. Another explanation for the effect of the workforce may involve energy expenditure at work or the structured lifestyle that active people impose.

Most of the studies showed that marriage is associated with obesity ${ }^{(46,47)}$. Iranian non-married women were less likely to be obese than their married counterparts. It is possible that the presence of a spouse may operate as a social factor on obesity. Women may have little time to spend on health behaviours. For example, they do not go to gyms and exercise centres ${ }^{(32)}$. It may also include physiological mechanisms in the women, especially after their pregnancy.

We found a statistically significant association between economic index and obesity in both sexes. An inverse relationship between BMI and socio-economic status exists in affluent societies, especially in women ${ }^{(18)}$. It is not a straightforward matter to compare those results with ours, because of the different study designs, time spans, regions, and methods of analysis. Our results are consistent with some studies in developing countries ${ }^{(48)}$. Note that we have no information on household income, but economic index is surrogate for household income. Iranian taxation laws are highly complex and inconsistently applied. There are virtually millions of people who do not pay taxes in Iran and hence operate outside the formal economy. Informal economy is an economic activity that is neither taxed nor monitored by a government; as opposed to a formal economy. Due to ethical considerations, we did not ask respondents about their income, because they were afraid of paying their taxes.

In developing countries, because of the transition of the population from rural to urban areas and owing to changing lifestyles, there is a trend for an increasing obesity rate. For example, over a period of less than 5 years, there was a significant increasing trend of obesity 
and overweight in the adult population of the Tehran Lipid Study ${ }^{(34)}$.

There are some advantages in our study. It was carried out in a nationally representative sample of Iranian men and women. To our knowledge, ours is the first study that had a sample size sufficient to study demographic and health behaviour factors and obesity in adult men and women in Iran. Height and weight were actually measured rather than self-reported. We used the same scales. The scales were calibrated on a daily basis. Self-reporting conditions might underestimate the prevalence of obesity. Obese persons are more likely to under-report their weights and over-report their heights than are non-obese persons and men are more likely to over-report their heights than are women, with both of these reporting patterns resulting in misclassification and leading to decreased calculated $\mathrm{BMI}^{(49,50)}$.

We used a large sample with high response rates. In Iran, the Ministry of Health and Medical Education is responsible for overall management of the public health system, and regulates the provision of private health services as well as NGOs. All Iranians are eligible for community-based preventive, public health, and limited curative health services financed and provided through the country's primary health care network. The network effectively reaches about $90 \%$ of the population and is particularly extensive in rural areas. Iran has 15400 health houses, 25000 behvarzes, 2200 rural health centres, 300 health posts and 1900 urban health centres. The behvarz is someone who works at health house. They know all households in rural areas.

Some households in the higher socio-economic classes in large cities such as Tehran did not participate in the present survey. If, at two different times, we realised that there was no one at home who could possibly be interviewed, another house in the neighbourhood was selected as the new sample unit. This bias was negligible.

Our findings are subject to several limitations. First, NHSI data are cross-sectional, so we were unable to draw conclusions regarding the causal association between sociodemographic factors, smoking and obesity. Second, income and physical activity were not used in our investigation although self-reporting income is subject to non-response and reporting bias. Third, marital status could be categorised into legally married and non-married only. Fourth, no validation of the smoking data could be achieved. However, there is evidence that a reporting bias according to smoking is negligible in population surveys ${ }^{(51)}$.

\section{Conclusions}

In summary, earlier research has shown the associations between sociodemographic factors, smoking and obesity among Iranian women. These results suggest similar associations among Iranian men. Increased age, low educational level, high economic index, being a nonsmoker and living in an urban environment, as well as inactivity in the workforce, were clearly associated with obesity among men. Our findings may point towards a better understanding of the social and cultural mechanisms of obesity in households. These sociodemographic factors are large contributors to obesity and provide the greatest opportunity for actions and interventions designed for prevention and treatment. A fundamental policy shift is required to widen responsibility for the prevention of obesity in Iran.

\section{Acknowledgements}

Funding support: The present study was financed by a grant from the Tehran University of Medical Science and Health Services. The authors acknowledge the National Health Survey for their data, coordinated at the Department of Biostatistics, School of Public Health and Institute of Public Health Research, Tehran University of Medical Science, Iran. Conflict of interest: The authors have no conflict of interest. Authors' contributions: E.B., K.M. and M.R.E. originated the idea for the present study, did the research proposal, data analysis and prepared the manuscript. Being the medical consultant, B.S. helped and edited the final version. All authors read and approved the final manuscript.

\section{References}

1. Popkin BM \& Doak CM (1998) The obesity epidemic is a worldwide phenomenon. Nutr Rev 56, 106-114.

2. World Health Organization (2000) Obesity: Preventing and Managing the Global Epidemic. Report of a WHO Consultation. WHO Technical Report Series no. 894. Geneva: WHO.

3. Rossner S (2002) Obesity: the disease of the twenty-first century. Int J Obes 6, Suppl. 4, S2-S4.

4. Ogden CL, Carroll MD, Curtin LR et al. (2006) Prevalence of overweight and obesity in the United States, 1999-2004. JAMA 295, 1549-1555.

5. European Men's Health Forum (2007) Obesity in men: a major problem for Europe. EMHF Fact Sheet. http:// www.emhf.org/resource_images /EMHF_ Fact sheet Obesity. Pdf (accessed 12 March 2007).

6. Birmingham CL, Mller JL, Palepu A et al. (1999) The cost of obesity in Canada. CMAJ 160, 483-488.

7. Australian Bureaus of Statistics (2001) National Health Survey. http://www.aihw.gov.au/publications/aus/bulletin08/ bulletin08.pdf

8. Kannel WB, D'Agosting RB \& Cobb JL (1996) Effect of weight on cardiovascular disease. Am J Clin Nutr 63, 195-225.

9. Van den Brandt PA, Spiegelman D \& Yaun SS (2000) Pooled analysis of prospective cohort studies on height, weight and breast cancer risk. Am J Epidemiol 152, 514-527.

10. Resnik HE, Valsania P, Halter JB et al. (2000) Relations of weight gain and weight loss on subsequent diabetes risk in overweight adults. J Epidemiol Community Health 54, 596-602.

11. Magnusson PKE, Rasmussen F, Lawlor DA et al. (2006) Association of body mass index with suicide mortality: a prospective cohort study of more than one million men. Am J Epidemiol 163, 1-8. 
12. Tikkinen KAO, Auvinen A, Huhtala H et al. (2006) Nocturia and obesity: a population-based study in Finland. $\mathrm{Am} \mathrm{J}$ Epidemiol 163, 1003-1011.

13. Yong LC, Kuller LH, Rutan G et al. (1993) Longitudinal study of blood pressure: changes and determinants from adolescence to middle age. The Dormont High School Follow-up Study, 1957-1963 and 1989-1990. Am J Epidemiol 138, 973-983.

14. Huang Z, Willet WC, Mancon JE et al. (1998) Body weight, weight change, and risk for hypertension in women. Ann Intern Med 128, 81-88.

15. Ford ES (1999) Body mass index and colon cancer in a national sample of adult US men and women. $A m J$ Epidemiol 150, 390-398.

16. Bagust A, Roberts BL, Haycox AK et al. (1999) The additional cost of obesity to the health service and the potential for resource savings from effective interventions. Eur J Public Health 9, 258-264.

17. Klumbiene J, Petkeviciene J, Helasoja V et al. (2004) Sociodemographic and health behaviour factors associated with obesity in adult populations in Estonia, Finland and Lithuania. Eur J Public Health 14, 390-394.

18. Sobal J \& Stunkard AJ (1989) Socioeconomic status and obesity: a review of the literature. Psychol Bull 105, 260-275.

19. The INCLEN Multicentre Collaborative Group (1994) Socioeconomic status and risk factors for cardiovascular disease: a multicentre collaborative study in the International Clinical Epidemiology Network (INCLEN). J Clin Epidemiol 47, 1401-1409.

20. Sarlio-Lahteenkorva S \& Lahelma E (1999) The association of body mass index with social and economic disadvantage in women and men. Int J Epidemiol 28, 445-449.

21. Laurier D, Guiguet M, Chau NP et al. (1992) Prevalence of obesity: a comparative survey in France, United Kingdom and the United States. Int J Obes 16, 565-572.

22. Molarius A, Seidell JC, San S et al. (2000) Educational level, relative body weight, and changes in their association over 10 years: an international perspective from the WHO MONICA Project. Am J Public Health 90, 1260-1268.

23. Wamala SP, Wolk A \& Orth-Gomer K (1997) Determinants of obesity in relation to socioeconomic status among middle-aged Swedish women. Prev Med 26, 734-744.

24. Reddy BN (1998) Body mass index and its association with socioeconomic and behavioural variables among socioeconomically heterogeneous populations of Andhra Pradesh, India. Hum Biol 70, 901-917.

25. Nube M, Asenso-Okyere WK \& van den Boom GJ (1998) Body mass index as indicator of standard of living in developing countries. Eur J Clin Nutr 52, 136-144.

26. Jeffery RW, Forster JL, Folsom AR et al. (1989) The relationship between social status and body mass index in the Minnesota Heart Health Program. Int J Obes 13, 59-67.

27. Kawada T (2004) Difference of body mass index stratified by the period of smoking cessation from a cross-sectional study. Arch Med Res 35, 181-184.

28. Laaksonen M, Rahkonen O \& Prattala R (1998) Smoking status and relative weight by educational level in Finland, 1978-1995. Prev Med 27, 431-437.

29. Rasky E, Stronegger WJ \& Freidl W (1996) The relationship between body weight and patterns of smoking in women and men. Int J Epidemiol 25, 1208-1212.

30. Molarius A, Seidell JC, Sans S et al. (1997) Smoking and relative body weight: an international perspective from the WHO MONICA Project. J Epidemiol Community Health $\mathbf{5 1}$, 252-260.

31. Saarni SE, Pietiläinen K, Kantonen S et al. (2009) Association of smoking in adolescence with abdominal obesity in adulthood: a follow-up study of 5 birth cohorts of Finnish twins. Am J Public Health 99, 348-354.
32. Bakhshi E, Eshraghian MR, Mohammad K et al. (2008) A comparison of two methods for estimating odds ratios: results from the National Health Survey. BMC Med Res Methodol 8, 78.

33. Bakhshi E, Eshraghian MR, Mohammad K et al. (2008) The positive association between number of children and obesity in Iranian women and men: results from the National Health Survey. BMC Public Health 8, 213.

34. Akhvan-Tiab A, Klishadi R, Sadri GH et al. (2003) Prevalence of obesity in central part of Iran. Healthy heart project. J Gazvin Univ of Med Sci 26, 27-35.

35. Azadbakht L, Mirmiran P \& Azizi F (2004) Prevalence and associates of obesity in Tehranian adults. Tehran Lipid Glucose Study. Int J Endocrinol Metab 5, Suppl. 1, 34-38.

36. Ghaderipour M, Mohamifard N, Asghari S et al. (2003) Prevalence of obesity and cardiovascular risk factors in Esfahan. J Ghazvin Univ Med Sci 26, 26-64.

37. Hajian-Tilaki KO \& Heidari B (2007) Prevalence of obesity, central obesity and the associated factors in urban population aged $20-70$ years, in the north of Iran: a population-based study and regression approach. Obes $\operatorname{Rev} \mathbf{8}, 3-10$.

38. Hajian-Tilaki KO \& Heidari B (2009) Association of educational level with risk of obesity and abdominal obesity in Iranian adults. J Public Health (Epublication ahead of print version).

39. Marques-Vidal $\mathrm{P}$, Bochud $\mathrm{M}$, Mooser $\mathrm{V}$ et al. (2008) Prevalence of obesity and abdominal obesity in the Lausanne population. BMC Public Health 8, 330.

40. Aekplakorn W, Hogan MC, Chongsuvivatwong V et al. (2007) Trends in obesity and associations with education and urban or rural residence in Thailand. Obesity (Silver Spring) 15, 3113-3121.

41. Jacoby E, Goldstein J, López A et al. (2003) Social class, family, and life-style factors associated with overweight and obesity among adults in Peruvian cities. Prev Med 37, 396-405.

42. Yoon YS, Oh SW \& Park HS (2006) Socioeconomic status in relation to obesity and abdominal obesity in Korean adults: a focus on sex differences. Obesity 14, 909-919.

43. Schooling CM, Jiang CQ, Lam TH et al. (2008) Life-course origins of social inequalities in metabolic risk in the population of a developing country. Am J Epidemiol 167, 419-428.

44. Kim MH, Kim MK, Choi BY et al. (2005) Educational disparities in the metabolic syndrome in a rapidly changing society - the case of South Korea. Int J Epidemiol 34, 1266-1273.

45. Mohtasham-Amiri Z, Maddah M, Nagshpour P et al. (2003) A study of obesity prevalence in middle age women in Rasht city/Iran. Proceeding of 2 nd congress of prevention of non-communicable diseases, Tehran. J Med Res Shahid Beheshti Univ Suppl 27, 260-265.

46. French SA \& Jeffery RW (1997) Current dieting, weight loss history, and weight suppression: behavioral correlates of three dimensions of dieting. Addict Behv 22, 31-44.

47. Jeffery RW, French SA, Forster JL et al. (1991) Socioeconomic status differences in health behaviors related to obesity: the Healthy Worker Project. Int J Obes 15, 689-696.

48. Griffiths P \& Bently M (2005) Women of higher socioeconomic status are more likely to be overweight in Karnataka, India. Eur J Clin Nutr 95, 1217-1220.

49. Palta M, Prineas RJ, Berman R et al. (1982) Comparison of self-reported and measured height and weight. $\mathrm{Am} \mathrm{J}$ Epidemiol 115, 223-230.

50. Rowland ML (1990) Self-reported weight and height. Am J Clin Nutr 52, 1125-1133.

51. Vartiainen E, Seppala T, Lillsunde P et al. (2002) Validation of self reported smoking by serum cotinine measurement in a community-based study. J Epidemiol Community Health 56, 167-170. 